\title{
Fertility Preservation for Prepubertal Patients at Risk of Infertility: Present Status and Future Perspectives
}

\author{
Valentina Pampanini ${ }^{a, b}$ Jasmin Hassan ${ }^{c}$ Elizabeth Oliver ${ }^{b}$ \\ Jan-Bernd Stukenborg ${ }^{b}$ Pauliina Damdimopoulou ${ }^{c}$ Kirsi Jahnukainen ${ }^{b, d}$ \\ aDipartimento Pediatrico Universitario Ospedaliero, Ospedale Pediatrico Bambino Gesù, Rome, Italy; ${ }^{b}$ Childhood \\ Cancer Research Unit, Department of Women's and Children's Health, NORDFERTIL Research Laboratory \\ Stockholm, Karolinska Institutet, and Karolinska University Hospital, Stockholm, Sweden; 'Division of Obstetrics \\ and Gynecology, Department of Clinical Science, Intervention and Technology, Karolinska Institutet, and Karolinska

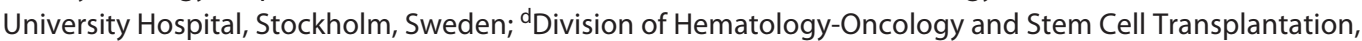 \\ Children's Hospital, University of Helsinki and Helsinki University Hospital, Helsinki, Finland
}

\section{Keywords}

Fertility preservation · Childhood · Cryopreservation · Cancer

\begin{abstract}
The increasing cure rate of cancer has led to a vast population of survivors having to face the late adverse effects of oncological treatments, with fertility impairment being one of the most sensitive issues for patients. Different options to preserve the fertility of adult patients are routinely used in clinical practice. However, fertility preservation strategies for prepubertal patients at risk of infertility are limited to the cryopreservation of immature gonadal tissue. In recent decades, many research efforts have been focused on the future use of cryopreserved gonadal tissue. This review discusses the common status of fertility preservation measures for pediatric patients undergoing gonadotoxic treatment, focusing especially on the challenges that remain to be solved in order to implement this fundamental service.
\end{abstract}

(c) 2021 S. Karger AG, Basel (c) 2021 S. Karger AG, Basel

www.karger.com/hrp

\section{Introduction}

Chemotherapy and radiotherapy are key treatments of both oncological and nononcological conditions. In recent decades, major advances in these treatments have led to a steady increase in childhood cancer survivors (CCS). According to the National Cancer Institute, the 5-year survival rate for all childhood cancer was $84.5 \%$ as of November 2019, and similar data have been reported for European countries [1]. As a consequence, there is a growing population of adult survivors that will face the longterm sideeffects of cancertreatments. Fertilityimpairment, arising from gonadal exposure to gonadotoxic treatments, is a major concern among cancer survivors. The treatments most commonly associated with primary gonadal failure in both boys and girls are high cumulative doses of alkylating agents and irradiation exposure of the gonads. Primary gonadal failure can coexist with central hypogonadism in patients affected by central nervous system tumors or exposed to high-dose cranial irradiation. Gonadal failure, induced by cancer treatments, translates clinically into impairment of growth, sexual development, and fertility. Today, fertility-saving options

\footnotetext{
Karger'
}

Correspondence to:

Valentina Pampanini, valentina.pampanini@opbg.net 
Table 1. Pediatric and adolescent cancer patients at risk of infertility who need counseling about fertility preservation

\begin{tabular}{|c|c|}
\hline Females & Males \\
\hline $\begin{array}{l}\text { High-dose alkylating agents, CED } \geq 6,000-8,000 \mathrm{mg} / \mathrm{m}^{2} \\
{[3,8-14]}\end{array}$ & $\begin{array}{l}\text { High-dose alkylating agents, CED } \geq 4,000 \mathrm{mg} / \mathrm{m}^{2} \\
\quad \text { or cisplatin (any dose) }[7,17,18]\end{array}$ \\
\hline RT ovaries $[8]$ & RT testes [7] \\
\hline Cranial RT $[4,15,16]$ & Cranial RT $[16,19]$ \\
\hline HSCT $[8]$ & HSCT [7] \\
\hline Oophorectomy $[13,14]$ & Orchidectomy \\
\hline
\end{tabular}

CED, cyclophosphamide equivalent dose; HSCT, hematopoietic stem cell transplantation.

before gonadotoxic exposure are clinically established only for patients who have undergone puberty. For prepubertal patients who do not produce mature gametes, the options are very limited. Ovarian and testicular tissue cryopreservation is the experimental procedure that is offered to prepubertal patients at risk of infertility in a number of countries worldwide. This minireview will focus on the current status of these approaches, their limitations, and future perspectives.

\section{Risk of Infertility in Pediatric Patients Undergoing Gonadotoxic Treatments}

As reported in the literature, impairment of fertility occurs in up to $30 \%$ of children treated with chemo- and/ or radiotherapy. This proportion rises considerably for patients who undergo hematopoietic stem cell transplantation (HSCT), which includes a combination of highdose alkylating agents with/without irradiation [2-6]. The risk of infertility has been established for the major gonadotoxic agents used in the treatment of pediatric cancer and should be carefully evaluated for proper fertility preservation counseling. Clinical surveillance and counseling regarding fertility risk are recommended for children exposed to one or more gonadotoxic treatments $[7,8]$. Fertility preservation options should always be discussed with the patients and their family when a high risk of infertility is identified (Table 1) [3, 4, 7-19].

\section{Female Patients}

Premature ovarian insufficiency (POI) is defined as the exhaustion of the ovarian follicles before the age of 40 years and is clinically characterized by primary or secondary amenorrhea (i.e., disappearance of menstrual cycle for $\geq 4$ months). During childhood, POI can present as lack of pubertal onset (absent breast development by age 13) or impairment of pubertal progression [8]. Elevated gonadotropins and low levels of estrogens, $\mathrm{AMH}$, and inhibin are common laboratory findings in POI [8]. The incidence of POI in CCS has been reported as $8-10 \%[13,20-22]$. Even those who retain ovarian function after treatment may experience decreased fertility rates. Alkylating agents such as cyclophosphamide, busulfan, and dacarbazine are associated with the highest risk of infertility, which increases proportionally with increased dose [23, 24]. Cyclophosphamide equivalent dose (CED) is a method based on a mathematical equation that estimates the cumulative dose of combined alkylating agents [25]. Different studies have explored the correlation between CED and the risk of POI. The risk of POI has been reported to significantly increase for CED values $>4,000$ or $>8,000 \mathrm{mg} / \mathrm{m}^{2}[12$, 25]. A recent study evaluating pregnancy in chemotherapy-only treated CCS reported a significantly lower likelihood of pregnancy with CED $\geq 11,295 \mathrm{mg} / \mathrm{m}^{2}$ (HR 0.85 , 95\% CI: $0.74-0.98 ; p=0.023$ ) [26]. The identification of a univocal safe threshold dose is undermined by confounding factors not included in the equation, such as radiotherapy exposure and individual factors. Gonad exposure to radiation is another significant risk factor for POI [27]. Threshold radiation doses for POI decrease with increasing age of the patient, corresponding to $20.3 \mathrm{~Gy}$ in infants, $18.4 \mathrm{~Gy}$ in children up to 10 years, $16.5 \mathrm{~Gy}$ in adolescents up to 20 years, and $14.3 \mathrm{~Gy}$ in older women $[24,28]$. The greater number of follicles present in younger patients or the higher resistance of the tissue may underlie the reduced susceptibility to radiotherapy. 


\section{Male Patients}

Lack of pubertal development (absent testicular volume increase $>4 \mathrm{~mL}$ after age 14) or progression is a common clinical manifestation of testicular failure in patients exposed to gonadotoxic treatments during childhood. As Leydig cells are more resistant than the germinal epithelium to chemo- and radiotherapy, spontaneous pubertal development may occur despite germ cell failure. Elevated gonadotropins, low inhibin B, oligo- or azoospermia, and reduced testicular volume are common features of impaired germ cell function. Alkylating agents and platinum-derived compounds bear the highest gonadotoxic potential [29]. Threshold doses for prolonged azoospermia have been defined for some of the most common chemotherapeutic agents $[29,30]$. Follow-up data of male survivors from the CCS Study cohort showed a decreased likelihood of siring a pregnancy (HR 0.63, 95\% CI: $0.58-$ 0.68 ; $p<0.0001)$ with a significant association with increasing CED (HR 0.82, 95\% CI: 0.79-0.86; $p<0.0001$ per $5,000 \mathrm{mg} / \mathrm{m}^{2}$ increments) [26]. Reduced fertility and azoospermia have been reported after exposure to CED between 4,000 and $7,500 \mathrm{mg} / \mathrm{m}^{2}[7,26,31]$. However, a safe CED threshold has not been defined [31]. Leydig cell damage is induced by lower irradiation doses in prepubertal patients compared to adult patients [32-34]. In the majority of the patients, testicular irradiation of $24 \mathrm{~Gy}$, used in relapsed leukemia, causes delayed sexual maturation and a need for androgen replacement therapy, reflecting Leydig cell failure [7,35]. A transient impairment of spermatogenesis has been detected after doses of 2-4 Gy of testicular irradiation. Recovery of spermatogenesis is possible in males after a variable period of azoospermia, as long as the spermatogonial cells are not completely depleted. Among patients exposed to CED $<9,500 \mathrm{mg} / \mathrm{m}^{2}$, $83 \%$ demonstrated such recovery, with a peak at $5-7$ years after the end of treatment [36]. Spermatogenic recovery has been reported 10-30 years following myeloablative HSCT but depends on the cumulative testicular irradiation dose as no recovery was observed in patients exposed to $>12$ Gy of irradiation dose [5].

\section{Options of Fertility Preservation and Future Challenges - Female Patients}

Oocyte and embryo cryopreservation is the established fertility preservation option for adult women. For prepubertal girls, ovarian tissue cryopreservation (OTC) is the only available fertility preservation method. The most common and feasible use of ovarian cortex fragments after OTC is tissue autografting to restore ovarian function and fertility. Since 2004, retransplantation of postpubertal ovarian tissue has resulted in more than 130 live births [37, 38]. Furthermore, a restoration of ovarian activity has been reported in $>95 \%$ of cases following retransplantation of cryopreserved ovarian tissue [39]. The described possibilities and effectiveness of OTC, together with the fact that it does not require sexual maturity or ovarian stimulation, demonstrates its potential for prepubertal patients [37, 40]. Nevertheless, scientific evidence of pregnancies stemming from transplanted child ovarian tissue is scant: there are only 2 cases where transplantation of premenarcheal pediatric ovarian tissue has led to pregnancy and live birth $[41,42]$. There are currently no reports on transplantation of tissue collected in early childhood, although tissue is being collected even from infants for this purpose $[43,44]$. The questions regarding fertility preservation in young girls are many, and continued research in this field is of paramount importance. Future research should focus on the identification of patients that will benefit the most from OTC, oocyte quality and puberty-induced changes in child ovary, success rate of transplantations, and suitable timeline for the procedure [45]. OTC prior to any treatment should be preferred whenever possible in order to guarantee the best tissue quality. At the same time, as OTC is an invasive procedure, it should only be offered to patients at high risk of infertility $(>50 \%)$, in order to maintain a fair riskbenefit ratio and allocate health resources properly. Some centers restrict OTC to an estimated risk of infertility $>80 \%$ [24]. Risk assessment for the OTC procedure encompasses both the intrinsic surgical risk (i.e., hemorrhagic or infectious complications) and the possible iatrogenic reduction of the ovarian reserve by removal of ovarian tissue harboring nongrowing follicles. However, the effect of OTC on ovarian function is negligible and definitively overcome by the risk of treatment-induced infertility when patients with $>80 \%$ risk of infertility are selected. When a selection criterion of $>50 \%$ infertility risk is applied, assessment of the risk-benefit ratio may be less straightforward and should take into account other factors, such as the age of the patient and the underlying disease. Removal of the whole ovary is the preferred surgical technique in young patients whose small ovaries do not allow multiple biopsies to harvest ovarian tissue. Although unilateral oophorectomy has been shown to only anticipate age at menopause of 1-2 years in normal women $[46,47]$, the additive effect of gonadotoxic treatments in cancer patients may not be negligible. Moreover, for 


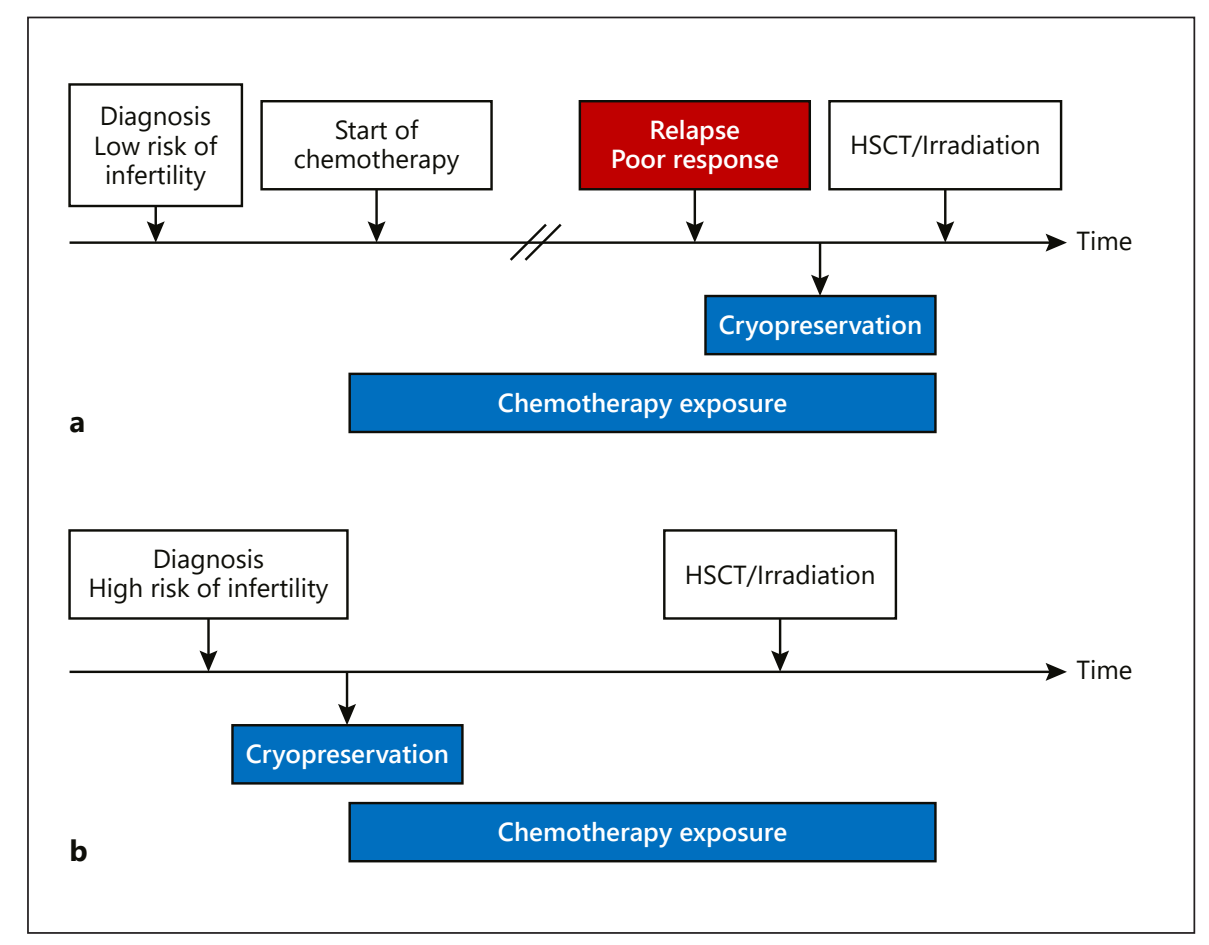

Fig. 1. Timeline of OTC according to fertility risk stratification at diagnosis. a Patients at low risk of infertility at diagnosis may evolve to high risk depending on the disease course (relapse/poor response). Ovarian tissue will have been exposed to chemotherapy at the time of OTC. $\mathbf{b}$ Patients at high risk of infertility already at diagnosis may undergo OTC before any treatment is started. OTC, ovarian tissue cryopreservation; HSCT, hematopoietic stem cell transplantation.

patients affected by diseases at risk of ovarian contamination, reimplantation of cryopreserved ovarian tissue is currently not recommended, and the uncertainty about the future use of harvested ovarian tissue should be taken into account in the evaluation of the risk-benefit ratio.

For some patients, a high risk of infertility emerges only after the first-line treatment proves inefficient or upon relapse (i.e., acute leukemia), which means that ovarian tissue has already been exposed to various treatments at the time of tissue harvest (shown in Fig. 1). Our studies have shown that even first-line treatments, considered at low risk for infertility, significantly damage ovarian stroma and follicles in young patients [48]. These results emphasize the importance of avoiding unnecessary delays in performing OTC. Although some chemotherapy exposure cannot be avoided for the lack of prognostic markers in the majority of cases, prompt identification and management of eligible patients is essential to limit the exposure to further chemotherapy.

Aside from oncological diseases, there has been an increasing demand for fertility counseling regarding nononcological illnesses where for instance conditioning therapies for HSCT bring a high risk of infertility. Increasing number of indications for fertility preservation pertain to nononcological diseases. In young patients, these often include hematological, immunological, and genetic conditions; however, it is currently not under- stood how these diagnoses impact the ovaries [49]. For patients with nonmalignant conditions, reduced intensity conditioning before HSCT has being increasingly used since 2000. Research on the gonadotoxic effects of these regimens as well as evidence of gamete quality in genetic disorders needs to be implemented. Fertility counseling in this group of patients deserves extra attention and should consider aspects such as genetic susceptibility to subfertility and treatment-related toxicity, the inheritance of underlying disease, and the effects of patients' primary disorder on future pregnancy and parenting. Multiple challenges related to the future use of cryopreserved ovarian tissue need to be addressed. A major task is to preserve the quality of the graft after enduring the mechanical processing, freezing, thawing, and transplantation. The initial follicular density is of great importance to the longevity of the graft $[50,51]$. A recent study demonstrated that the loss of ovarian follicles during the whole OTC and transplantation procedure is around $80 \%$ [52]. The great majority of follicle loss occurs after retransplantation of the tissue and is directly related to the revascularization window. Several strategies have been explored to preserve the follicles upon autografting, such as delivering angiogenic and antiapoptotic factors, antioxidants, and adipose-derived stem cells to increase vascularization and decrease ischemia after tissue grafting [53-58]. Although some of these strategies show great po- 


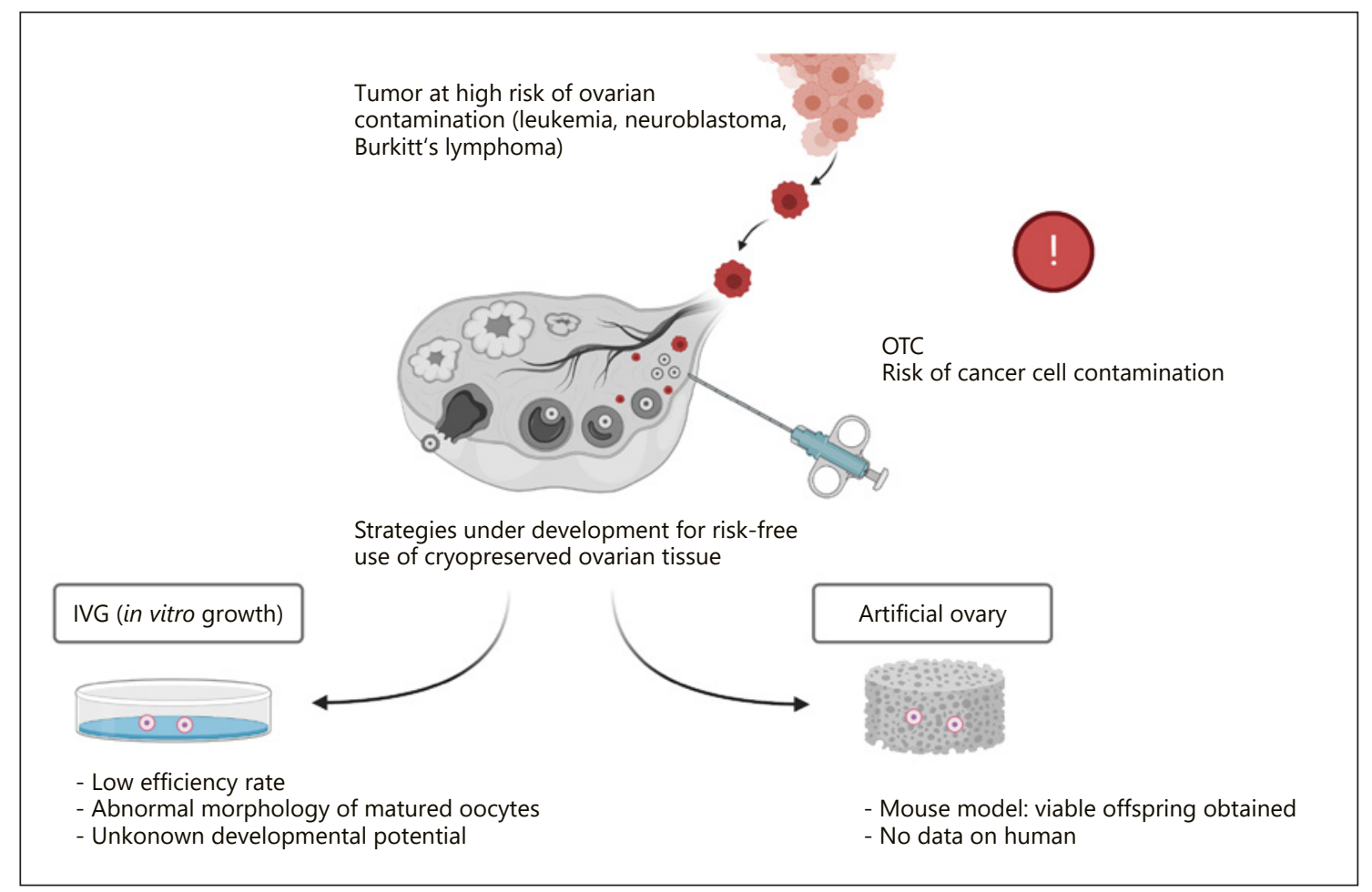

Fig. 2. Techniques to restore fertility in girls with cancer diseases at risk of ovarian contamination. Created with BioRender.com. OTC, ovarian tissue cryopreservation.

tential, they have not been shown to lead to statistically significant improvements. Finally, autografting ovarian tissue from patients with systemic diseases, such as leukemia, neuroblastoma, and Burkitt's lymphoma, carries the risk of reintroducing malignant cells that might have contaminated the ovaries before OTC [59]. For this reason, ovarian tissue transplantation is currently not recommended in these cases. However, young patients may still benefit from OTC with the hope that future advances in techniques will avoid reseeding of contaminating cancer cells. Patients and their families should be transparently informed about this risk and the current status of alternative techniques. Among different methods under investigation to circumvent this limitation (shown in Fig. 2), a promising strategy is the in vitro maturation of nongrowing cortical follicles. Full maturation of follicles isolated from the adult ovarian cortex to metaphase II oocytes has been reported using a multistep culture system. Low efficiency rate of oocyte maturation and evidence of morphological abnormalities in the matured oocytes are yet major unsolved limitations [60]. Importantly, although follicle density is higher in child ovarian tissue, abnormal follicle morphology is more frequently observed paired with poorer survival in culture compared to adults [61,
62]. Further optimization of culture methods is clearly needed for child (and adult) tissue. An alternative approach to preserve fertility and avoid the risk of disease recurrence after transplantation is the so-called artificial ovary. Nongrowing follicles isolated from ovarian tissue are transferred into scaffolds forming an artificial unit that can be transplanted to orthotopic sites. Scaffold matrixes tested range from fibrin clots to decellularized ovaries and 3D-printed biopolymer networks [63-65]. Studies on human artificial ovaries have been conducted on adult tissue, and no follicle growth has been demonstrated so far $[63,64]$. Another future possibility for fertility preservation is the generation of oocytes from stem cells. Oogonial stem cells have been widely discussed over the past decade, but their existence and function in human ovaries is still debated [66,67]. Instead, other types of stem cells could be considered. In mice, functional oocytes have been created from pluripotent stem cells [68, 69]. These oocytes could be fertilized, and one study resulted in healthy pups [68]. Advances in the development of human germ line in vitro have been more modest compared to mouse [70], placing this vision undoubtedly far in the future. A clear limitation of all experimental studies involving child ovarian tissue is the availability of such 


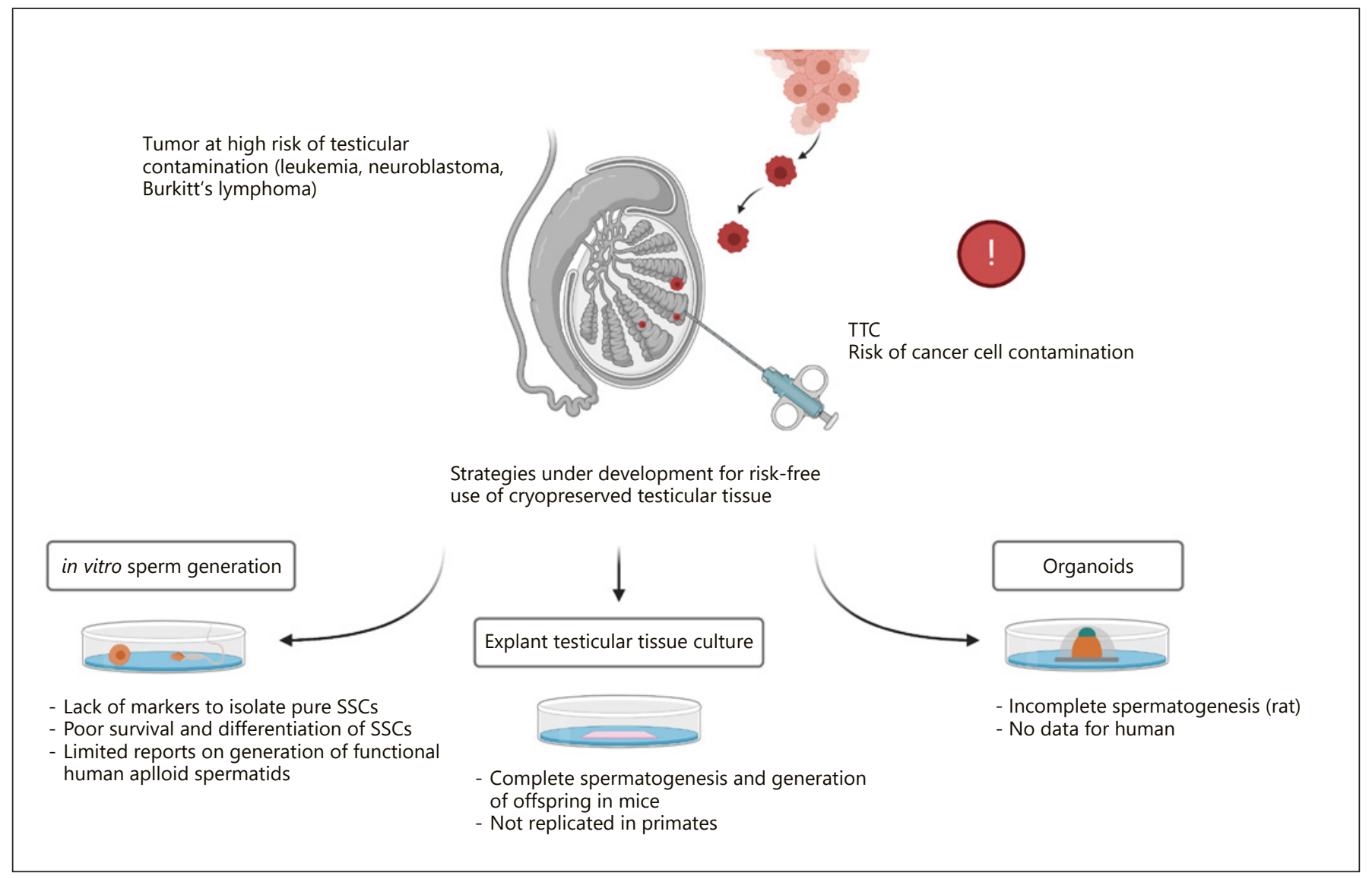

Fig. 3. Techniques to restore fertility in boys with cancer diseases at risk of testicular contamination. Created with BioRender.com. SSCs, spermatogonial stem cells.

samples for research. The patients are few, and large international collaborations will be needed to enable cohorts of sufficient size for statistical analyses. Some burning questions future studies could tackle, even with limited material, would be puberty-induced changes in ovarian tissue and follicle quality by using advanced single-cell analysis technologies. An in-depth molecular understanding of normal ovarian tissue including follicles would be an invaluable reference dataset when evaluating normality of cultured tissue and in vitro-generated oocytes.

\section{Options of Fertility Preservation and Future Challenges - Male Patients}

Pubertal patients at risk of treatment-induced infertility can be offered semen cryopreservation. Sperm is found in $50 \%$ of boys by the age of 14 years and a testicular vol- ume between 8 and $15 \mathrm{~mL}$ [71]. Thus, cryopreservation of sperm should be considered when testicular volume is above 10-12 mL. Current strategies to preserve fertility in prepubertal boys center around the cryopreservation of testicular material [72]. However, the success of this approach to restore subsequent fertility is dependent on the preservation of germ cells with stem cell capability within the cryopreserved tissue. This means that tissue collection must be well timed in order to minimize the impact of the disorder or treatment on spermatogonia populations. Surgical removal of testis tissue is an invasive procedure and must be balanced against the relative risk of infertility. As such, continued stratification of fertility risks based on underlying diagnoses and treatment is necessary to validate and, if necessary, adapt patient selection criteria to avoid unnecessary surgery in those who would subsequently retain natural fertility. This could be achieved through multicenter follow-up studies employing standardized protocols [72]. 
Despite an increasing number of centers worldwide offering storage of testis tissue, strategies for the subsequent generation of viable sperm, including autologous testicular tissue grafting, spermatogonial stem cells (SSC) transplantation, and in vitro spermatogenesis, remain experimental. Autologous testis tissue grafting has resulted in the generation of nonhuman primate offspring [73] and appears a likely frontrunner for entry into pilot clinical trials; however, proof of concept has yet to be demonstrated in humans. When translated to the clinic, the approach poses the risk of reintroducing malignancies and may not be appropriate for survivors of childhood leukemia, lymphoma, or other hematologically metastasizing malignant diseases. To overcome this, technologies allowing for cell sorting and elimination of malignant cells or prior screening for residual cancer cells will be required. Xenotransplantation studies with human immature testicular tissue demonstrate the onset of germ cell differentiation; however, there is often an accompanying loss of spermatogonia attributed to limited revascularization between graft and host [74, 75]. To improve vascularization and spermatogonial survival, current studies are focused on combining tissue transplantation with angiogenic factors such as vascular endothelial growth factor [76, 77]. SSC transplantation is considered the only method that could lead to restoration of fertility by natural conception. SSC transplantation has been demonstrated to re-establish spermatogenesis in nonhuman primates resulting in viable embryos [78]. If treatment or disease has led to damage of the somatic environment within the seminiferous tubule, SSC transplantation may not be sufficient to restore fertility. In such cases, cotransplantation of SSCs with functional niche cells may improve the efficiency of fertility restoration [79]. An additional limitation of SSC transplantation comes with the relatively small number of SSCs present in the human testis. While limited in vitro propagation of human prepubertal SSCs has been reported, functional proof that the SSCs generated are able to reinitiate spermatogenesis is still lacking [80]. A further obstacle is the lack of defined markers required to identify and isolate pure populations of SSCs from other cells, including those which may be malignant. At present, options to restore fertility in individuals with metastasizing diseases are restricted to strategies enabling the generation of sperm in vitro for subsequent use in assisted reproductive technology (shown in Fig. 3). Only a limited number of studies have described the generation of functional human haploid spermatids from SSCs capable of developing into embryos after round spermatid injection in murine oocytes [81, 82]. A functional somatic microenvironment resembling the $3 \mathrm{D}$ organization of the testis may benefit the survival and differentiation of male germ cells in vitro $[83,84]$. Based on murine studies, 3-dimensional conditions such as explant testicular tissue culture appear the most promising strategy and have resulted in complete spermatogenesis and the generation of offspring from immature testis fragments [85]. To date, this approach has not been replicated in primates; however, the generation of human haploid germ cells from testicular tissue samples of prepubertal cancer patients has been reported [86]. Further research focused on better understanding the mechanisms underlying human spermatogenesis will be required to design a system to support the process in vitro. As a tool for investigation, organoids represent a potential strategy for more detailed examination of testicular physiology [84]. Gametes derived from patientspecific pluripotent stem cells would eliminate the need for harvesting patient tissue as well as providing an opportunity for those without germ cells to father their own biological children. However, current protocols require improvement in terms of both reproducibility and robustness in order to be considered for future clinical use [87].

\section{Conclusions}

To date, cryopreservation of ovarian and testicular tissue is the only available option to preserve fertility in prepubertal patients who do not produce mature gametes. While cryopreservation of ovarian tissue has already proven clinically valid in terms of fertility restoration, at least for adult women, equivalent techniques for cryopreserved testicular tissue have not yet reached the stage of clinical application. In both cases, major challenges need to be addressed, especially for the pediatric population. Research protocols are the essential support for the development of current methods and need to be implemented in every center where fertility preservation programs are performed. Together with fertility risk assessment, transparent information should be given to patients and their families by healthcare professionals about the experimental nature of fertility preservation strategies and the ongoing research in the field.

\section{Conflict of Interest Statement}

The authors have no conflicts of interest to declare. 


\section{Funding Sources}

No funding sources were used to produce this review.

\section{Author Contributions}

Valentina Pampanini conceived and designed the work. All the authors drafted the work, revised it for important intellectual content, and gave the final approval of the version to be published. All the authors agree to be accountable for all aspects of the work in ensuring that questions related to the accuracy or integrity of any part of the work are appropriately investigated and resolved.

\section{References}

1 Trama A, Bernasconi A, McCabe MG, Guevara $M$, Gatta $G$, Botta $L$. Is the cancer survival improvement in European and American adolescent and young adults still lagging behind that in children? Pediatr Blood Cancer. 2019;66(1):e27407.

2 Balcerek M, Reinmuth S, Hohmann C, Keil T, Borgmann-Staudt A. Suspected infertility after treatment for leukemia and solid tumors in childhood and adolescence. Dtsch Ärztebl Int. 2012;109(7):126-31.

3 Borgmann-Staudt A, Rendtorff R, Reinmuth S, Hohmann C, Keil T, Schuster FR, et al. Fertility after allogeneic haematopoietic stem cell transplantation in childhood and adolescence. Bone Marrow Transplant. 2012;47(2): 271-6.

4 Green DM, Kawashima T, Stovall M, Leisenring W, Sklar CA, Mertens AC, et al. Fertility of female survivors of childhood cancer: a report from the childhood cancer survivor study. J Clin Oncol. 2009;27(16):2677-85.

5 Mathiesen S, Sørensen K, Nielsen MM, Suominen A, Ifversen M, Grell K, et al. Male gonadal function after allogeneic hematopoietic stem cell transplantation in childhood: a cross-sectional, population-based study. Biol Blood Marrow Transplant. 2020;26(9):163545.

6 Rendtorff R, Hohmann C, Reinmuth S, Müller A, Dittrich R, Beyer M, et al. Hormone and sperm analyses after chemo- and radiotherapy in childhood and adolescence. Klin Pädiatr. 2010;222(3):145-9.

7 Skinner R, Mulder RL, Kremer LC, Hudson MM, Constine LS, Bardi E, et al. Recommendations for gonadotoxicity surveillance in male childhood, adolescent, and young adult cancer survivors: a report from the international late effects of childhood cancer guideline harmonization group in collaboration with the PanCareSurFup consortium. Lancet Oncol. 2017;18(2):e75-90.

8 van Dorp W, Mulder RL, Kremer LC, Hudson MM, van den Heuvel-Eibrink MM, van den Berg MH, et al. Recommendations for premature ovarian insufficiency surveillance for female survivors of childhood, adolescent, and young adult cancer: a report from the international late effects of childhood cancer guideline harmonization group in collaboration with the PanCareSurFup consortium. J Clin Oncol. 2016;34(28):3440-50.

9 Laverdiere C, Liu Q, Yasui Y, Nathan PC, Gurney JG, Stovall M, et al. Long-term out- comes in survivors of neuroblastoma: a report from the Childhood Cancer Survivor Study. J Natl Cancer Inst. 2009;101(16):1131-40.

10 Thomas-Teinturier C, Allodji RS, Svetlova E, Frey MA, Oberlin O, Millischer AE, et al. Ovarian reserve after treatment with alkylating agents during childhood. Hum Reprod. 2015;30(6):1437-46.

11 Bresters D, Emons JA, Nuri N, Ball LM, Kollen WJ, Hannema SE, et al. Ovarian insufficiency and pubertal development after hematopoietic stem cell transplantation in childhood. Pediatr Blood Cancer. 2014;61(11): 2048-53.

12 Chemaitilly W, Li Z, Krasin MJ, Brooke RJ, Wilson CL, Green DM, et al. Premature ovarian insufficiency in childhood cancer survivors: a report from the St. Jude lifetime cohort. J Clin Endocrinol Metab. 2017;102(7): 2242-50.

13 Levine JM, Whitton JA, Ginsberg JP, Green DM, Leisenring WM, Stovall M, et al. Nonsurgical premature menopause and reproductive implications in survivors of childhood cancer: a report from the Childhood Cancer Survivor Study. Cancer. 2018;124(5): 1044-52.

14 Thomas-Teinturier C, El Fayech C, Oberlin $\mathrm{O}$, Pacquement $\mathrm{H}$, Haddy N, Labbé $\mathrm{M}$, et al. Age at menopause and its influencing factors in a cohort of survivors of childhood cancer: earlier but rarely premature. Hum Reprod. 2013;28(2):488-95.

15 Reulen RC, Zeegers MP, Wallace WH, Frobisher C, Taylor AJ, Lancashire ER, et al. Pregnancy outcomes among adult survivors of childhood cancer in the British Childhood Cancer Survivor Study. Cancer Epidemiol Biomarkers Prev. 2009;18(8):2239-47.

16 Chemaitilly W, Li Z, Huang S, Ness KK, Clark KL, Green DM, et al. Anterior hypopituitarism in adult survivors of childhood cancers treated with cranial radiotherapy: a report from the St Jude Lifetime Cohort study. J Clin Oncol. 2015;33(5):492-500.

17 Jahnukainen K, Heikkinen R, Henriksson M, Cooper TG, Puukko-Viertomies LR, Mäkitie O. Semen quality and fertility in adult longterm survivors of childhood acute lymphoblastic leukemia. Fertil Steril. 2011;96(4):83742.

18 Green DM, Zhu L, Wang M, Chemaitilly W, Srivastava D, Kutteh WH, et al. Effect of cranial irradiation on sperm concentration of adult survivors of childhood acute lympho- blastic leukemia: a report from the St. Jude Lifetime Cohort Studydagger. Hum Reprod. 2017;32(6):1192-201.

19 Gan HW, Phipps K, Aquilina K, Gaze MN, Hayward R, Spoudeas HA. Neuroendocrine morbidity after pediatric optic gliomas: a longitudinal analysis of 166 children over 30 years. J Clin Endocrinol Metab. 2015;100(10): 3787-99.

20 Anderson RA, Brewster DH, Wood R, Nowell S, Fischbacher C, Kelsey TW, et al. The impact of cancer on subsequent chance of pregnancy: a population-based analysis. Hum Reprod. 2018;33(7):1281-90.

21 Green DM, Sklar CA, Boice JD, Mulvihill JJ, Whitton JA, Stovall M, et al. Ovarian failure and reproductive outcomes after childhood cancer treatment: results from the Childhood Cancer Survivor Study. J Clin Oncol. 2009; 27(14):2374-81.

22 Sklar CA, Mertens AC, Mitby P, Whitton J, Stovall M, Kasper C, et al. Premature menopause in survivors of childhood cancer: a report from the childhood cancer survivor study. J Natl Cancer Inst. 2006;98(13):890-6.

23 Lee SJ, Schover LR, Partridge AH, Patrizio P, Wallace WH, Hagerty K, et al. American Society of clinical oncology recommendations on fertility preservation in cancer patients. J Clin Oncol. 2006;24(18):2917-31.

24 Wallace WH, Anderson RA, Irvine DS. Fertility preservation for young patients with cancer: who is at risk and what can be offered? Lancet Oncol. 2005;6(4):209-18.

25 Green DM, Nolan VG, Goodman PJ, Whitton JA, Srivastava D, Leisenring WM, et al. The cyclophosphamide equivalent dose as an approach for quantifying alkylating agent exposure: a report from the Childhood Cancer Survivor Study. Pediatr Blood Cancer. 2014; 61(1):53-67.

26 Chow EJ, Stratton KL, Leisenring WM, Oeffinger KC, Sklar CA, Donaldson SS, et al. Pregnancy after chemotherapy in male and female survivors of childhood cancer treated between 1970 and 1999: a report from the Childhood Cancer Survivor Study cohort. Lancet Oncol. 2016;17(5):567-76.

27 Chemaitilly W, Mertens AC, Mitby P, Whitton J, Stovall M, Yasui Y, et al. Acute ovarian failure in the childhood cancer survivor study. J Clin Endocrinol Metab. 2006;91(5):1723-8.

28 Wallace WH, Thomson AB, Kelsey TW. The radiosensitivity of the human oocyte. Hum Reprod. 2003;18(1):117-21. 
29 Meistrich ML. Effects of chemotherapy and radiotherapy on spermatogenesis in humans. Fertil Steril. 2013;100(5):1180-6.

30 Jahnukainen K, Stukenborg JB. Clinical review: present and future prospects of male fertility preservation for children and adolescents. J Clin Endocrinol Metab. 2012;97(12): 4341-51.

31 Green DM, Liu W, Kutteh WH, Ke RW, Shelton KC, Sklar CA, et al. Cumulative alkylating agent exposure and semen parameters in adult survivors of childhood cancer: a report from the St Jude Lifetime Cohort Study. Lancet Oncol. 2014;15(11):1215-23.

32 Kenney LB, Cohen LE, Shnorhavorian M, Metzger ML, Lockart B, Hijiya N, et al. Male reproductive health after childhood, adolescent, and young adult cancers: a report from the Children's Oncology Group. J Clin Oncol. 2012;30(27):3408-16

33 Lee SH, Shin $\mathrm{CH}$. Reduced male fertility in childhood cancer survivors. Ann Pediatr Endocrinol Metab. 2013;18(4):168-72.

34 Shalet SM, Tsatsoulis A, Whitehead E, Read G. Vulnerability of the human leydig cell to radiation damage is dependent upon age. J Endocrinol. 1989;120(1):161-5.

35 Brauner R, Czernichow P, Rappaport R. Greater susceptibility to hypothalamopituitary irradiation in younger children with acute lymphoblastic leukemia. J Pediatr. 1986; 108(2):332.

36 Pryzant RM, Meistrich ML, Wilson G, Brown $\mathrm{B}$, McLaughlin P. Long-term reduction in sperm count after chemotherapy with and without radiation therapy for non-Hodgkin's lymphomas. J Clin Oncol. 1993;11(2):239-47.

37 Donnez J, Dolmans MM. Fertility preservation in women. N Engl J Med. 2017;377(17) 1657-65.

38 Jensen AK, Macklon KT, Fedder J, Ernst E, Humaidan P, Andersen CY. 86 successful births and 9 ongoing pregnancies worldwide in women transplanted with frozen-thawed ovarian tissue: focus on birth and perinatal outcome in 40 of these children. J Assist Reprod Genet. 2017;34(3):325-36.

39 Donnez J, Dolmans MM, Diaz C, Pellicer A. Ovarian cortex transplantation: time to move on from experimental studies to open clinical application. Fertil Steril. 2015;104(5):1097-8.

40 Oktay K, Harvey BE, Partridge AH, Quinn GP, Reinecke J, Taylor HS, et al. Fertility preservation in patients with cancer: ASCO clinical practice guideline update. J Clin Oncol. 2018;36(19):1994-2001.

41 Demeestere I, Simon P, Dedeken L, Moffa F, Tsépélidis S, Brachet C, et al. Live birth after autograft of ovarian tissue cryopreserved during childhood. Hum Reprod. 2015;30(9): 2107-9.

42 Matthews SJ, Picton H, Ernst E, Andersen CY. Successful pregnancy in a woman previously suffering from $\beta$-thalassemia following transplantation of ovarian tissue cryopreserved before puberty. Minerva Ginecol. 2018;70(4) $432-5$.
43 Jensen AK, Rechnitzer C, Macklon KT, Ifversen MR, Birkebæk N, Clausen N, et al. Cryopreservation of ovarian tissue for fertility preservation in a large cohort of young girls: focus on pubertal development. Hum Reprod. 2017;32(1):154-64.

44 Poirot C, Brugieres L, Yakouben K, PradesBorio M, Marzouk F, de Lambert G, et al. Ovarian tissue cryopreservation for fertility preservation in 418 girls and adolescents up to 15 years of age facing highly gonadotoxic treatment. Twenty years of experience at a single center. Acta Obstet Gynecol Scand. 2019;98(5):630-7.

45 Nahata L, WoodruffTK, Quinn GP, Meacham LR, Chen D, Appiah LC, et al. Ovarian tissue cryopreservation as standard of care: what does this mean for pediatric populations? J Assist Reprod Genet. 2020;37(6):1323-6.

46 Bjelland EK, Wilkosz P, Tanbo TG, Eskild A. Is unilateral oophorectomy associated with age at menopause? A population study (the HUNT2 Survey). Hum Reprod. 2014;29(4):835-41.

47 Wilkosz P, Greggains GD, Tanbo TG, Fedorcsak P. Female reproductive decline is determined by remaining ovarian reserve and age. PLoS One. 2014;9(10):e108343.

48 Pampanini V, Wagner M, Asadi-Azarbaijani B, Oskam IC, Sheikhi M, Sjödin MOD, et al. Impact of first-line cancer treatment on the follicle quality in cryopreserved ovarian samples from girls and young women. Hum Reprod. 2019;34(9):1674-85.

49 Condorelli M, Demeestere I. Challenges of fertility preservation in non-oncological diseases. Acta Obstet Gynecol Scand. 2019;98(5):638-46.

50 Andersen CY, Silber SJ, Bergholdt SH, Jorgensen JS, Ernst E. Long-term duration of function of ovarian tissue transplants: case reports. Reprod Biomed Online. 2012;25(2): $128-32$.

51 Donnez J, Dolmans MM. Ovarian cortex transplantation: 60 reported live births brings the success and worldwide expansion of the technique towards routine clinical practice. J Assist Reprod Genet. 2015;32(8):1167-70,

52 Roness H, Meirow D. FERTILITY PRESERVATION: follicle reserve loss in ovarian tissue transplantation. Reproduction. 2019; 158(5):F35-f44.

53 Gao J, Huang Y, Li M, Zhao H, Zhao Y, Li R, et al. Effect of local basic fibroblast growth factor and vascular endothelial growth factor on subcutaneously allotransplanted ovarian tissue in ovariectomized mice. PLoS One. 2015;10(7):e0134035

54 Kang BJ, Wang Y, Zhang L, Xiao Z, Li SW. bFGF and VEGF improve the quality of vitrified-thawed human ovarian tissues after xenotransplantation to SCID mice. J Assist Reprod Genet. 2016;33(2):281-9.

55 Mahmoodi M, Soleimani Mehranjani M, Shariatzadeh SM, Eimani H, Shahverdi A. Nacetylcysteine improves function and follicular survival in mice ovarian grafts through inhibition of oxidative stress. Reprod Biomed Online. 2015;30(1):101-10.
56 Manavella DD, Cacciottola L, Pommé S, Desmet CM, Jordan BF, Donnez J, et al. Two-step transplantation with adipose tissue-derived stem cells increases follicle survival by enhancing vascularization in xenografted frozen-thawed human ovarian tissue. Hum Reprod. 2018;33(6):1107-16.

57 Soleimani R, Heytens E, Oktay K. Enhancement of neoangiogenesis and follicle survival by sphingosine-1-phosphate in human ovarian tissue xenotransplants. PLoS One. 2011; 6(4):e19475.

58 Tavana S, Valojerdi MR, Azarnia M, Shahverdi A. Restoration of ovarian tissue function and estrous cycle in rat after autotransplantation using hyaluronic acid hydrogel scaffold containing VEGF and bFGF. Growth Factors. 2016;34(3-4):97-106.

59 Bastings L, Beerendonk CC, Westphal JR, Massuger LF, Kaal SE, van Leeuwen FE, et al. Autotransplantation of cryopreserved ovarian tissue in cancer survivors and the risk of reintroducing malignancy: a systematic review. Hum Reprod Update. 2013;19(5):483506

60 McLaughlin M, Albertini DF, Wallace WHB, Anderson RA, Telfer EE. Metaphase II oocytes from human unilaminar follicles grown in a multi-step culture system. Mol Hum Reprod. 2018;24(3):135-42.

61 Anderson RA, McLaughlin M, Wallace WH, Albertini DF, Telfer EE. The immature human ovary shows loss of abnormal follicles and increasing follicle developmental competence through childhood and adolescence. Hum Reprod. 2014;29(1):97-106.

62 Asadi Azarbaijani B, Sheikhi M, Oskam IC, Nurmio M, Laine T, Tinkanen H, et al. Effect of previous chemotherapy on the quality of cryopreserved human ovarian tissue in vitro. PLoS One. 2015;10(7):e0133985.

63 Chiti MC, Dolmans MM, Orellana O, Soares $\mathrm{M}$, Paulini F, Donnez J, et al. Influence of follicle stage on artificial ovary outcome using fibrin as a matrix. Hum Reprod. 2016;31(12): 2898-35.

64 Pors SE, Ramløse M, Nikiforov D, Lundsgaard K, Cheng J, Andersen CY, et al. Initial steps in reconstruction of the human ovary: survival of pre-antral stage follicles in a decellularized human ovarian scaffold. Hum Reprod. 2019;34(8):1523-35.

65 Laronda MM, Rutz AL, Xiao S, Whelan KA, Duncan FE, Roth EW, et al. A bioprosthetic ovary created using $3 \mathrm{D}$ printed microporous scaffolds restores ovarian function in sterilized mice. Nat Commun. 2017;8:15261.

66 Wagner M, Yoshihara M, Douagi I, Damdimopoulos A, Panula S, Petropoulos S, et al. Singlecell analysis of human ovarian cortex identifies distinct cell populations but no oogonial stem cells. Nat Commun. 2020;11(1):1147.

67 White YA, Woods DC, Takai Y, Ishihara O, Seki H, Tilly JL. Oocyte formation by mitotically active germ cells purified from ovaries of reproductive-age women. Nat Med. 2012; 18(3):413-21. 
68 Hikabe O, Hamazaki N, Nagamatsu G, Obata Y, Hirao Y, Hamada N, et al. Reconstitution in vitro of the entire cycle of the mouse female germ line. Nature. 2016;539(7628):299-303.

69 Hamazaki N, Kyogoku H, Araki H, Miura F, Horikawa C, Hamada N, et al. Reconstitution of the oocyte transcriptional network with transcription factors. Nature. 2021;589(7841): 264-9.

70 Yamashiro C, Sasaki K, Yabuta Y, Kojima Y, Nakamura T, Okamoto I, et al. Generation of human oogonia from induced pluripotent stem cells in vitro. Science. 2018;362(6412): 356-60.

71 Kulin HE, Frontera MA, Demers LM, Bartholomew MJ, Lloyd TA. The onset of sperm production in pubertal boys. Relationship to gonadotropin excretion. Am J Dis Child. 1989;143(2):190-3.

72 Goossens E, Jahnukainen K, Mitchell RT, van Pelt A, Pennings G, Rives N, et al. Fertility preservation in boys: recent developments and new insights ( $\dagger$ ). Hum Reprod Open. 2020;2020(3):hoaa016.

73 Fayomi AP, Peters K, Sukhwani M, Valli-Pulaski H, Shetty G, Meistrich ML, et al. Autologous grafting of cryopreserved prepubertal rhesus testis produces sperm and offspring. Science. 2019;363(6433):1314-9.

74 Van Saen D, Goossens E, Aerts JL, Haentjens $\mathrm{P}$, Tournaye H. Does early cell death cause germ cell loss after intratesticular tissue grafting? Fertil Steril. 2013;99(5):1264-e1.
75 Van Saen D, Goossens E, Bourgain C, Ferster A, Tournaye $\mathrm{H}$. Meiotic activity in orthotopic xenografts derived from human postpubertal testicular tissue. Hum Reprod. 2011;26(2): 282-93.

76 Poels J, Abou-Ghannam G, Decamps A, Leyman M, Rieux Ad, Wyns C. Transplantation of testicular tissue in alginate hydrogel loaded with VEGF nanoparticles improves spermatogonial recovery. J Control Release. 2016; 234:79-89.

77 Ntemou E, Kadam P, Van Laere S, Van Saen D, Vicini E, Goossens E. Effect of recombinant human vascular endothelial growth factor on testis tissue xenotransplants from prepubertal boys: a three-case study. Reprod Biomed Online. 2019;39(1):119-33.

78 Hermann BP, Sukhwani M, Winkler F, Pascarella JN, Peters KA, Sheng Y, et al. Spermatogonial stem cell transplantation into rhesus testes regenerates spermatogenesis producing functional sperm. Cell Stem Cell. 2012;11(5):715-26.

79 Shetty G, Mitchell JM, Lam TNA, Wu Z, Zhang J, Hill L, et al. Donor spermatogenesis in de novo formed seminiferous tubules from transplanted testicular cells in rhesus monkey testis. Hum Reprod. 2018;33(12):2249-55.

80 Sadri-Ardekani H, Akhondi MA, van der Veen F, Repping S, van Pelt AM. In vitro propagation of human prepubertal spermatogonial stem cells. JAMA. 2011;305(23):2416-
81 Sun M, Yuan Q, Niu M, Wang H, Wen L, Yao $\mathrm{C}$, et al. Efficient generation of functional haploid spermatids from human germline stem cells by three-dimensional-induced system. Cell Death Differ. 2018;25(4):747-64.

82 Yang S, Ping P, Ma M, Li P, Tian R, Yang H, et al. Generation of haploid spermatids with fertilization and development capacity from human spermatogonial stem cells of cryptorchid patients. Stem Cell Reports. 2014;3(4): 663-75.

83 Oliver E, Stukenborg JB. Rebuilding the human testis in vitro. Andrology. $2020 \mathrm{Jul} ; 8(4)$ : 825-834.

84 Alves-Lopes JP, Stukenborg JB. Testicular organoids: a new model to study the testicular microenvironment in vitro? Hum Reprod Update. 2018 Mar 1;24(2):176-191.

85 Sato T, Katagiri K, Gohbara A, Inoue K, Ogonuki N, Ogura A, et al. In vitro production of functional sperm in cultured neonatal mouse testes. Nature. 2011;471(7339):504-7.

86 de Michele F, Poels J, Vermeulen M, Ambroise J, Gruson D, Guiot Y, et al. Haploid germ cells generated in organotypic culture of testicular tissue from prepubertal boys. Front Physiol. 2018;9:1413.

87 Kurek M, Albalushi H, Hovatta O, Stukenborg JB. Human pluripotent stem cells in reproductive science-a comparison of protocols used to generate and define male germ cells from pluripotent stem cells. Int J Mol Sci. 2020;21(3):1028. 